\title{
African Heritage: A True Asset
}

\author{
Alfredo M. RONCHI \\ EC MEDICI Framework, Corso Buenos Aires 20, Milano, 20124, Italy \\ Tel: +39 393 0629373, Fax: +3902 2399 6080, Email: alfredo.ronchi@polimi.it
}

\begin{abstract}
Globalisation is one of the key terms used to describe actual trends as positive, but there are many aspects of this concept that should be carefully considered, such as people's cultural identity. Africa is one of the most diverse and culturally rich continents in the world, something that is not widely known. Heritage is one of the building blocks of cohesion and solidarity of the society and in addition is one of the national resources that can contribute in the gross national income. It is acting as ambassador of the country and at the same time enriching the international community with new instances of culture. The present document describes a proposal in order to establish digital humanities curricula in the African continent and preserve, manage and exploit African Culture. The paper includes the description of the role of communication methodologies and formats enabled and empowered by information.
\end{abstract}

Keywords: globalisation, cultural diversity, cultural values, digital humanities, eCulture.

\section{Introduction}

Years ago we all entered, willing or not, the age of globalisation. This does not only mean to drink Cuban Mojito in South Korea or enjoy Malaysian craftsmanship in Switzerland but involves deep changes in a wide range of sectors (cultural, linguistic, economic, artistic, and more). The planet never looked so small like today, people is travelling across continents and oceans apace. The recent significant increase, even if relatively modest compared with the population, of travellers coming from new emerging economies such as China, India and Brazil gave acceleration to such a process. In this context Africa is since a long time an appreciated touristic destination offering to visitors a wide range of unique experiences.

On the cultural and social side [13] there is something positive associated to globalisation, people knows much more about other inhabitants of the planet, their culture, their issues; all these aspects enrich our opportunity to analyse facts, events and behaviours thanks to multiple viewpoints. This may contribute to a peaceful future. Globalisation at the same time refers to dominant languages and cultures; this aspect may endanger local languages and culture. If on one side a global market enables multiple trading on the other side a homogeneous language and culture simplifies the business. The Universal Declaration on Cultural Diversity (UNESCO General Conference 2001) states, "cultural diversity as a source of exchange, innovation and creativity is just as indispensable for humanity as biological diversity for nature, and is a treasure shared by the entire human race". If this is not enough we can add that diversity is always a patrimony, richness, it means "life", on the opposite uniformity means sometimes "death". Even in the creative world of moviemakers the idea of "hell" in the future is tightly connected with uniformity, absence of diversity; the Henry Ford free choice of colour as long as it's black.

It is a common understanding that people who grow up in different cultures do not just think about different things, they actually think differently. The environment and culture in which people are raised affects and even determines many of their thought processes. 
Africa is one of the most diverse and culturally rich continents in the world, something that is not widely known. The world knows much about some ancient civilizations, but not much about African ancient civilizations in a broad sense. Digital technologies may help to show the rich cultural patrimony of Africa to the world and to Africa itself. This process must be activated directly involving young generations through new curricula addressed to transfer specific competences in the field of eCulture and Digital Humanities. This process will promote heritage preservation and sustainable exploitation, mutual understanding, job creation, tourism, local economy and more.

Of course cultural identity and history must be considered as a positive value strengthening peaceful cooperation and human relations, not as the opportunity to revitalize ancient misunderstanding and conflicts.

An overview of the paper structure may be summarized as follows: next section "Objectives" will outline the relevance to preserve cultural diversity and heritage with specific reference to the African continent and its actual situation, a wide set of objectives will be illustrated including those pertaining to the educational and employment fields.

Section "Methodology" will illustrate a basic methodology positively experienced both in Europe and far eastern countries in order to provide a clear vision about potential values related to heritage in a broad sense.

Section "The role of communication and technologies" stresses the relevance of effective communication formats and summarizes some of the key technologies already experienced in wide range of situations and provides some hints regarding emerging trends in tight relation with feasibility and sustainability in the specific environment.

Section Four describes the emerging professional profiles due to the implementation of the basic idea outlined in section "Objectives". Section Six draws some conclusions and future plans.

\section{Objectives: Preservation and Exploitation of Cultural and Linguistic Diversity in the African Continent}

The relevance to preserve cultural and linguistic diversity is well known to everyone interested in culture. UNESCO, apart from the afore mentioned Universal Declaration on Cultural Diversity, thanks to the Information for All Programme (IFAP) is actively supporting this goal through aimed initiatives.

As already stated Africa is no doubt one of the richest continents in cultural and linguistic diversity. Different populations and tribes are the custodians of languages, traditions, rituals, and habits. Despite of this very few has been done in order to support and protect such assets, of course there are far more "basic" needs to be satisfied in this continent you may say.

Linguistic and cultural diversity in cyberspace [3] was one of the priorities identified on the occasion of the WSIS. One of the most relevant initiatives is "MAAYA World Network for Linguistic Diversity" a multilateral network created to contribute to the enhancement and promotion of linguistic diversity in the world. The MAAYA Network was founded in the context of the recent World Summit on the Information Society (WSIS), thanks to the strong commitment of a group o experts leaded by Amb. Adama Samasseku former Minister of Culture in Mali. MAAYA was initiated by the African Academy of Languages $\left(A C A L A N{ }^{1}\right)$ whose mission is "Fostering Africa's integration and development through the development and promotion of the use of African languages in all domains of life in Africa"; ACALAN operates under the auspices of the African Union. At present, the Network serves as the moderator of the sub-theme on Linguistic Diversity of the action line

\footnotetext{
${ }^{1}$ www.acalan.org - affiliate Institution: Department for Social Affairs of the African Union Commission
} 
C8 of the WSIS Plan of Action [14] and has initiated the Dynamic Coalition for Linguistic Diversity ${ }^{2}$ of the Internet Governance Forum $\left(\mathrm{IGF}^{3}\right)$ [11].

Languages are stores of a rich and vast amount of human heritage and knowledge, as well as necessary instruments for social life, the expression and dissemination of social and cultural traditions, self-identification and preservation of human dignity of their speakers. Languages and culture [2] of different "nations" contributes to the promotion of tolerance and mutual understanding and guarantees a peaceful sustainable development of the contemporary civilization.

Even if language and culture are tightly connected and preserving languages means in some way preserving related culture, no similar initiative has been taken in the field of African culture and heritage in general and few have been undertaken at national level.

We are conscious that cultural and linguistic diversity [10] is the edge of an iceberg that includes cultural identities, sense of belonging to a community, personal root, intangible heritage, popular knowledge and achievements throughout the centuries, proper interpretation of local content and much more.

One of the main objectives of this document is to promote the creation of digital humanities curricula in African universities. An additional related objective to be achieved in parallel is to promote the active preservation, management and sustainable exploitation of local heritage (natural, mixed, cultural, ... intangible).

\section{Methodology: Heritage as a True Asset}

Heritage in a broad sense is a true asset, some African countries benefit mainly from the natural one some more from the cultural some from both but there are large areas where such an asset it is not taken into account and exploited even at local level. To do not mention attempts to "erase" heritage both physically and historically. It is a must to identify, preserve, protect and exploit in a sustainable way national heritage might it be natural, cultural, mixed or even intangible. We stress the intangible heritage because this is widely present in African culture and it is usually very "fragile". Heritage together with culture and language is a true human asset and as an asset must be managed.

We must thank our ancestors because they preserved and transferred to future generations what we term now "heritage". Such a task was probably easier in the past on a less populated planet having less need for food, energy, and territory; nowadays globalisation, mass tourism and economic interests may threaten our heritage. Heritage in general is fragile and may be jeopardised by humans.

To get to the point let us take under consideration natural heritage, forests, mountains, deserts, lakes, rivers and wildlife of course, it represents a local irreplaceable resource; it is patrimony of local people but may even represent a significant attractor for other people may be belonging to the same country or foreigners, so far we consider it "patrimony of humanity". Natural and mixed heritage are strictly connected with the preservation of the environment, pollution, illegal waste management and more in general inappropriate regulations and interventions may irremediably damage them [6] [7].

Our heritage it is not only due to natural resources, though the centuries humans created monuments, artefacts, rituals, music and songs and much more [o]. According with UNESCO taxonomy such part of heritage is termed "cultural heritage". The preservation of

\footnotetext{
2 http://www.intgovforum.org/cms/dynamic-coalitions/73-linguistic-diversity

${ }^{3} \mathrm{http}: / /$ www.intgovforum.org/cms/ "The Internet Governance Forum (IGF) serves to bring people together from various stakeholder groups as equals, in discussions on public policy issues relating to the Internet. While there is no negotiated outcome, the IGF informs and inspires those with policy-making power in both the public and private sectors. At their annual meeting delegates discuss, exchange information and share good practices with each other. The IGF facilitates a common understanding of how to maximize Internet opportunities and address risks and challenges that arise."
} 
cultural heritage is extremely important as it represents those materials from the memory of individuals and nations with all its cultural values and history.

Dealing with heritage usually one of the first tasks to accomplish is to document these materials in order to set up a national register for each branch of heritage and keep it for successive generations. All these tasks, preservation, exploitation etc. may be activated only if we are able to discover and identify heritage and its "values". So let's talk about the "Value" methodology".

\subsection{Identifying Values}

"Each time cultural heritage contributes to artistic, educational or social development, it is a source of value: aesthetic value, experience value, existence value; its production implies economic movement, and not to take this into consideration would lead to a lack of fundamental understanding" (MCC 2003) [1].

The origins of the concept of value in the cultural field are very different from those related to economy; the value of cultural heritage can be considered, such as the set of its aesthetic, artistic and historical qualities. Compared to the economics' cultural values are more susceptible to change over time and geographical location.

The present paragraph will outline the concept of "values" related to heritage in a broad sense and the other different elements actively contributing to the overall appreciation and fruitful exploitation of our legacy. Of course this paragraph will simply provide some hints about "Value" methodology and refers to the specific documentation for further details.

Why do we need to develop a specific methodology to identify "values", why it is so relevant? Of course there is not a unique approach to cultural heritage protection, promotion and valorisation. The evolution of communication's techniques and methods now enables a more effective action on citizens. Potential cultural heritage' users can be better involved thanks to a more efficient communication strategy. The changing patterns of communication caused the crisis of various disciplines and Institutions, as we can see, as fairly obvious, in schools and more in general in educational Institutions.

\subsection{Value Matrix Main Entries}

In a very short way we can consider the matter of values as the complex interaction among different aspects:

- Heritage typology (natural, cultural, mixed, intangible, ...);

- Wide set of "values" (economic value, ROI, social, cultural, exceptionality/uniquely, etc.);

- Geographic range (valuable for locals, national, regional, global, non local mainly);

- Potential users (experts, specialists, collectors, businessmen, citizens, researchers, community members, etc.).

Major parts of these values are "potential"; some times there is no chance or need to monetize them. As many time happens the "effects" of the "values" are shared among different actors in the value-chain some times not including the public body looking after the cultural assets. Many times it happens that the one who covers the expenses it is not the one who earns much money from the "fruition" of the cultural asset; it is a kind of asymmetric market model. Moreover sometimes the full set of values it is not evident at least to the managers or it is not considered proper or "wise" to take advantage from them.

This aspect is often due to the fact that cultural institutions usually do not include management and business profiles mainly focusing on curators and conservators. It is the

\footnotetext{
${ }^{4}$ Refer to JPI - JHEP JOINT PILOT TRANSNATIONAL CALL for Joint Research Projects on Cultural Heritage: project "SMART VALUE"
} 
never-ending conflict between "culture" and "money". Moreover sometimes it happens that the relevance or value of such assets it is not recognised by locals, may be because is part of their everyday life, foreigners are needed in order to identify such values.

Sometimes the outcomes coming from the exploitation and fruition of heritage do not benefit local population. It happens both physically in case of touristic organisations "all inclusive" and virtually when documentaries and television programmes are created on the basis of local heritage without any compensation policy, the latest is usually termed "biopiracy".

Sometimes the value is significant only for a specific target group, may be locals, foreigners or collectors, on the opposite, sometimes it is evident at global level that means that is a patrimony of humanity as we use to term it. Long-term traditions and rituals may strengthen cultural identity; natural scenarios, historical palaces or classic cars may be extremely valuable as movie film locations and elements of the scene. Well-crafted video documentation of restoration works or archaeological excavations may provide both relevant revenues and visibility to cultural assets as it happened in recent times for Egyptian excavations leaded by Dr. Zahi Hawass [c].

Such an approach will not only maximise the economic impact (economic value, return of investment, market-induced, etc.) but even cultural and social aspects (cultural identity, appreciation, customer loyalty, sense of belonging, minorities, etc., etc.).

The exploitation of such values will not, necessarily, jeopardize our heritage, cultural assets are not rivalling and a wise exploitation will not "consume" them. On the contrary a clear identification of their "values" will help to identify and protect them creating the basic conditions to ensure a proper exploitation. Such a scenario looks like a win-win agreement, citizens may benefit from the fruitful exploitation of their own heritage, and stakeholders may benefit from enhanced visibility and incomes. The cultural heritage, in the broad sense and in all its forms, is the bearer of a multitude of values: historical, witness, nationality, civilization recognition, cultural identity, traditions, arts, science, conservation and technology. More recently eno-gastronomic values came to the fore so both bare DOP DOCG etc. products; local food and even historical recipes and products became relevant assets.

\subsection{Establishing These Values}

The plurality of values associated to a cultural "object", however, is widening according to the variety of stakeholders who consider themselves part of the process of fruition, conservation and management of heritage.

Establishing these values [9] when making decisions concerning the assets and, therefore, satisfy the needs of different stakeholders, turns out to be of crucial importance, mainly because they are the "seeds" to be exploited in order to increase the attractiveness of a given territory. Therefore Heritage refers to a heterogeneous demand to be recognized in its many components, in order to investigate the space of values in its global extension, space that, as we shall see later, is delimited by the different needs of its differentiated demand. Except that, in order to do so, there is a need to identify and define the tools and methods of measurement and assessment of heritage in the different perspectives of the value attributable to it. In this perspective, the cultural heritage is:

- a multivalued good / service, in the sense that it belongs to different dimensions of meaning (for example, economic and cultural) in which it receives different values by different stakeholders that are interfaced to it;

- a multifunctional good / service, meaning they can be used for different purposes (e.g. educational, touristic and social) based on the values of which it includes; 
- a resource in an economic sense, as it can be used to create a set of services for the production or exploitation, producing continuous streams of income, resource, however, must be properly "maintained" to ensure that production remains useful;

- $\quad$ "a resource for sustainable development and the quality of life in a society in constant evolution"5;

- a public resource (or private involving public interest), which is declined at the same time with the quality of "local" - or in a territory, and closely linked to it - and with the quality of the "global" - as understood by UNESCO. This dual aspect leads, in fact, in the neologism "glocal";

- a good / meritorious service, which the community assigns particular functional and moral value plus social development of the community itself;

- a valuable information, because its value is intrinsic in the message it sends to those who benefit;

- "... all those things that deserve our interest and that, therefore, survive and maintain thanks to this interest and because of the advantages, both material and spiritual, which we derive" 6

\section{The Role of Communication and Technologies}

The role of technology [5] is it is mainly related to on the shelf technologies than on research, "communication" methodologies are the real field of research. As a consequence, we will mainly focus on communication methodologies and formats of course strongly enhanced or enabled by technological advances. How to better "communicate" and attract people toward culture and heritage ${ }^{7}$. We don't need "highways" without cars, libraries without books, technology per se [15].

Referring to the classic taxonomy proposed by researchers "objects" may be mainly subdivided between "tools" and "communication objects". Through the centuries significant "tools" loose their practical utility and may turn into "communication objects" as it happened for roman masonry tools or Galileo's telescopes.

Artefacts and archaeological remains are mainly "communication objects", so they must "communicate" something to visitors. The communication process associated with cultural heritage involves a reasonable degree of complexity. Some of the main intrinsic difficulties in the cultural heritage communication process arise from the fact that the work of art usually pertains to a different historical and cultural context, from its integrity and conservation; indeed, many of them are no more located in the original place and their original location may be not accessible anymore.

How many times have we have seen descriptions such as "Terracotta FragmentSecond Century", objects removed from their usual context or function, and artefacts on display without a "code" that can help us to understand their function or meaning? How to let people improve their own knowledge thanks to effective means.

In collecting, preserving, and exploiting cultural heritage we must adequately take into account that heritage does not simply refer to objects, images or text-based descriptions. Examples of such cultural representations in the African continent may include life practices, such as the use of space and time, which are closely associated with different agricultural models ${ }^{8}$ or even nomadic lifestyle. These practices include female-based ${ }^{9}$

\footnotetext{
${ }^{5}$ Preamble, the Council of Europe Framework Convention on the Value of Cultural Heritage for the company, signed in Faro (PT) October 27, 2005

${ }^{6}$ Urbani Giovanni, speech on the occasion: "Colloquio internazionale CIHA sulle responsabilità dello storico nella conservazione e nel restauro dei monumenti e delle opere d'arte" (un-published), Venezia, 1967

7 Natural heritage too may take advantage from "communication", portable devices providing information about local wildlife, plants or guiding on trails and sightseeing tours.

${ }^{8}$ The Mark of Uru, Nigeria - https://www.youtube.com/watch?v=flbYy_erIXs
} 
culture and economic activities, indigenous medicine [p] [q] [r], the creation and use of hand tools, cultural adaptation to diverse geographies and climates, and indigenous knowledge. All of these rely not just on static objects or spaces, but also on movements through household, communal, agricultural, and forest spaces for a variety of interlinked purposes. Conventional databases, as well as conventional data-gathering techniques, have so far failed to adequately capture the intangibles of space, movement and indigenous knowledge. We must design specific formats and tools in order to preserve, communicate and transfer to future generation such intangible heritage [n].

In the framework of "multi-values" and "multi-functionality" of heritage we can explore a wide range of additional values mainly related to recent technologies and trends [4]. The opportunity to fully enjoy the added values offered by emerging technologies may represent an additional set of values, why not? ${ }^{10}[17]$

Multimedia [g], digital story telling, accessibility"1, "sharebility" [h], and the transmission of information from any location to another in a practical and fast way: these are the current needs of the different users of heritage and cultural services. 3D models and animations [d], virtual reality and, thanks to position aware systems [1] such as tablets and phones, enhanced reality applications $[\mathrm{a}][\mathrm{b}]$ may offer a valuable contribution to the visitors of both immovable heritage but even natural [f], movable or intangible heritage. African culture is very rich of intangible assets; legends, stories, rituals and performing arts play a key role. An interesting experience has been carried out years ago recreating the 3D model of the territory ${ }^{12}$ starting from the memories and legends patrimony of the different tribes that use to live on that portion of the country and tagging different locations accordingly with the contribution of each chief of tribe [i][m].

As story telling [e] is usually one of the most appreciated ways to promote heritage to a broad audience, digital story telling helps much to reach and "evangelize" people, it is a powerful tool for cultural mediators [18]. Furthermore another relevant contributor is a kind of collateral output of excavations or restoration processes, usually termed "making of" that is to say a well crafted video representing and commenting the full process as is or enriched with digital imagery ${ }^{13}$. There are some interesting examples of this approach developed for instance in $\mathrm{Egypt}^{14}$ or China ${ }^{15}$.

Let's consider an historical location, let's say an ancient settlement, one approach is to provide a short presentation about the village itself a different approach is to introduce the historical context and feeling of the time thanks to a story or a relevant fact that happened there. It is a common understanding that people memorize stories and event better than bare data. Once the interest of the visitor is captured it will be possible to introduce other relevant information that complement the historical and social environment plus some technical data. This means that at the end of the process the visitor enjoys some added value and he or she will probably remember it for a long time as a positive experience ${ }^{16}$.

So far a mixture of natural or cultural heritage plus a portion of intangible heritage [n] such as stories, legends ${ }^{17}$ or simply rituals may be the right cocktail to attract and involve a

\footnotetext{
${ }^{9}$ The African Queens Project, Tanzania - http://africanqueensproject.com

10 A couple of interesting "historical" applications: The Smithsonian without walls: Revealing Things (http://www.thinkmap.com/pressrelease.jsp?id=67) and Historywired (http://historywired.si.edu)

11 e.g. digital technologies enable virtual access to protected environments suffering anthropic risks or "non accessible" sites such as caves or underwater archaeological remains.

12 Collaborative Resource Use Planning and Safeguarding Intangible Cultural Heritage in Fiji - 3D Participatory GIS http://www.iapad.org/applications/plup/ovalau.htm

${ }^{13}$ It may become e relevant source of revenues if sold to television companies such as Discovery Channel.

14 TV Reality Series "Chasing Mummies" by Dr. Zahi Hawass - promo https://www.youtube.com/watch?v=1yLMHtC2vuc

15 The Emperor's Secret Garden (2010) https://www.youtube.com/watch?v=_fxJ0xEoY8I

16 APA L'etrusco, CINECA Bologna - http://www.cineca.it/it/video/apa-alla-scoperta-di-bologna-i-primi-minuti-delcartoon-3d

${ }^{17}$ Misteri di Venezia - http://nuovostudio.it/misteridivenezia/booktrailer.html
} 
number of visitors in heritage. Such a strategy may be considered as a win-win strategy, better cultural experience for end users and sustainability for stakeholders.

To conclude and summarize technological aspects, there is enough technology on the shelf in order to provide added value services, most of it, if we focus on end users, is already available in the African continent.

The real challenge is to enable the creation of local content and services by locals and reduce as much as possible related costs. In Europe after decades of huge investments in the field of eCulture and eLearning and Education, many times artificially vitalising projects sentenced to death, focus is now posed on added value and sustainable services enabled by on the shelf technologies and access to a reasonable communication infrastructure.

\section{Emerging Professional Profiles}

The main professional profiles generated by the present twofold initiative are: expert in heritage conservation, expert in heritage exploitation, cultural mediators, and expert in heritage management. The main predictable outcomes and impacts are the creation of new job opportunities, better protection and sustainable exploitation of local and continent wide heritage.

Education and training are the basic steps required to understand and protect cultural identities and heritage. We cannot be found of something we don't know. A true commitment to preserving cultural assets comes from knowledge and understanding. Furthermore, in order to fully enjoy the opportunities unleashed by technology, a fruitful cooperation must be established between technologists and experts in cultural heritage.

One strategic issue associated with the utilisation of applications and services from the ICT and emerging technologies market in the cultural heritage sector is the availability of persons with specific professional profiles; we need to pay particular attention to these profiles and define suitable study curricula at various levels. One of the key professional profiles in this sector is "cultural mediator". The mission of this profile is to act as a bridge between different cultural models, different societies and last but not relevant ages.

The specific field of "cultural content communication through new information technologies" [16] is strongly based on a multidisciplinary approach, including the basics of computer science, multimedia, computer graphics, data acquisition, legal aspects and IPR, social sciences, psychology and cognitive sciences, visual communication, pedagogy and more. Up to now there have been almost no opportunities to match these competencies with existing courses at both graduate and postgraduate levels.

Such profiles are usually built on top of traditional curricula by achieving cross-sector competencies through self-managed ad hoc training processes. The starting points are mainly traditional courses, such as architecture, art history, cultural heritage, archaeology, and, less frequently, computer science.

Professionals can acquire some of the required interdisciplinary competencies by taking postgraduate courses. Of course, the cocktail of competencies required must be tuned to the specific field of interest: conservation, communication, education, etc.

More recently, apart from the Digital Humanities branch, some new and specific courses in digital communication have been created, with sub-branches in education, culture, entertainment, etc. These courses can be studied as first and second-level degrees and sometimes to $\mathrm{PhD}$ level. This revised educational approach represents the first step towards a completely new set of careers. This approach matches particularly in the African country were the state of the art and local issues are represents the best opportunity to take advantage from a similar initiative. 


\section{Conclusions and Future Developments}

Education, preservation and exploitation these are the main keywords identifying this document. African countries must fully benefit from heritage both creating local competences thanks to appropriate digital humanities curricula and starting well-defined preservation and exploitation activities supported by international experts and institutions. Moreover the establishment of digital humanities courses and training all-over the African continent will preserve cultural identity and heritage, promote tourism, contribute to national gross profit through new job opportunities and careers.

The diffusion and support of digital humanities curricula in parallel with African heritage management and exploitation will benefit all African countries creating new professional profiles, jobs and companies.

The opportunity to cooperate with western experts and Institutions in accomplishing these tasks provides a relevant benefit to African partners letting them avoid to reinvent the wheel, negative experiences, waste of resources and obsolete or non-performing solutions. Cutting edge sustainable solutions may be applied to African heritage in order to align the African heritage domain to the international standards.

A pilot implementation of digital humanities curricula has been already carried out in an African country with positive results. On the basis of this experience, thanks to a long-term participation in IFAP activities, a complete proposal has been recently submitted to the UNESCO Information for All Program.

\section{References}

\section{Bibliography}

[1] MCC (2003) Culture et development, No 141. Ministere de la Culture et du Communication (MCC), Direction de l'administration générale, Département des études et de la prospective, Paris

[2] Net.Lang: Towards a Multilingual Cyberspace, C\&F editions 2014

[3] Linguistic and Cultural Diversity in Cyberspace. Proceedings of the 2nd International Conference, ISBN 978-5-91515-048-7, Interregional Library Cooperation Centre, Moscow 2012

[4] Alfredo M. Ronchi, eCulture: cultural content in the digital age, ISBN 978-3-540-75273-8, Springer 2009

[5] Eleanor Fink, A.M. Ronchi, et Al., On Culture in a world wide information society", MEDICI 2001

[6] Nypan Terje, et al., European Legislation and Cultural Heritage, University of Primoska, 2012

[7] Nypan Terje, et al., EU directives \& cultural heritage, Deleywa Milan 2008

[8] Roko Zarnic, et al., Histcape, ISBN 978-961-6884-21-1, National University Ljubljana, 2014

[9] Alfredo M. Ronchi, Axiology in the domain of heritage: The concept of „Values” and its potential impact, proceedings «Boundaries of memory: Museum and Heritage of modern culture », St.-Petersburg State University and The State Hermitage, Sankt Petersburg, 2014

[10] Alfredo M. Ronchi, Is the Internet a melting pot?, III International conference: Linguistic and Cultural Diversity in Cyberspace, UNESCO IFAP Yakutsk, 2014 and outcomes of the Expert meeting at UNESCO on Multilingualism in Cyberspace (October 28-29 2014)

[11] The Third International Conference on Linguistic and Cultural Diversity in Cyberspace has completed its work in the capital of the Republic of Sakha (Yakutia), UNESCO IFAP 2014

[12] Alfredo M. Ronchi, Digital Natives, Netizens, eCommunities. Civitas Solis or Nightmare?, proceedings and report "Internet and Socio-Cultural Transformations in Information Society" UNESCO IFAP, Sakhalin, 2013

[13] The Sakhalin declaration on Internet and socio-cultural transformations, UNESCO IFAP 2013

[14] C8 Cultural diversity and identity, linguistic diversity and local content, WSIS Geneva, ITU. 2014

[15] Ranjit Makkuni, Syncretic technologies. The learning potential of cross-cultural, non-textual interactive art: the case of Ranjit Makkuni's Planet Health Museum in Delhi - Dspace.mah.se

[16] Ranjit Makkuni, Eternal Gandhi: Design of the Multimedia Museum. ISBN 9788175256422, Aditya Birla Group, 2007

[17] Yehuda Kalay, Thomas Kvan, Janice Affleck, New Heritage: New Media and Cultural Heritage, ISBN 9781135977719, Routledge, 2007

[18] Selma Rizvic, Story Guided Virtual Cultural Heritage Applications, Journal of Interactive Humanities, Vol. 2 [2014], Iss. 1, Art. 2, Published by RIT Scholar Works. 


\section{On line references}

a) Jumièges 3D - http://www.abbayedejumieges.fr

b) Ancient Aquileia 3D - http://vimeo.com/111506565 or https://play.google.com/store/apps/details?id=it.Ikon.AquileiaVirtuale.android

c) TV Reality Series "Chasing Mummies" by Dr. Zahi Hawass - promo https://www.youtube.com/watch?v=1yLMHtC2vuc

d) APA L'etrusco, CINECA Bologna - http://www.cineca.it/it/video/apa-alla-scoperta-di-bologna-i-primiminuti-del-cartoon-3d

e) Misteri di Venezia - http://nuovostudio.it/misteridivenezia/booktrailer.html

f) Grand Canal Venice - Officinie Panottiche http://www.canalview.it/allegati/CV_broc_sh.pdf or http://www.canalview.it/blog/

g) The Book of Secrets / Kitab Al-Asrar Fi Natayij Al-Afkar - Leonardo 3 https://www.leonardo3.net/bookofsecrets/index_eng.html

h) See, for example, http://www.louvre.edu

i) Collaborative Resource Use Planning and Safeguarding Intangible Cultural Heritage in Fiji - 3D Participatory GIS - http://www.iapad.org/applications/plup/ovalau.htm

j) The Mark of Uru, Nigeria - https://www.youtube.com/watch?v=flbYy_erIXs

k) The African Queens Project, Tanzania - http://africanqueensproject.com

1) "N2Ktag" an app for the venetian lagoon: http://www.n2ktag.com/it_IT

m) Applying Participatory - GIS and Participatory Mapping .... ftp://ftp.itc.nl/pub/pgis/PGIS\%20Articles/ Bibliographies/PGIS\%20Biblio_1.PDF

n) Shashi Bala, Digital inventories on Cultural Memories and Intangible Cultural Heritage: Case study of Yadav community of Haryana, India, CIDOC Proceedings http://network.icom.museum/fileadmin/ user_upload/minisites/cidoc/ConferencePapers/2012/bala.pdf

o) Ranjit Makkuni, Musical Landscapes and the Goddess Happening; New Interfaces, https://competition.adesignaward.com/design.php?ID=32723

p) Planet Health Museum, New Delhi, http://www.oneindia.com/2010/10/12/healthminister-azadinaugurates-planet-health-museum-in.html

q) MUSME - Digital Museum of Medicine, http://www.musme.it videoclips https://www.youtube.com/watch?v=TwRYtO2q3iU https://www.youtube.com/watch?v=NU8mF6NLeSg

r) Beijing Digital Museum of Traditional Chinese Medicine, by Beijing Traditional Chinese Medicine International Exchange and Cooperating Center (BTCMIECC), www.tcm-china.info 